\title{
Sodalite cages of EMT zeolite confined neutral molecular-like silver clusters
}

\author{
Biao Dong a, b, Richard Retoux ${ }^{\text {c }}$, Vincent de Waele ${ }^{\mathrm{d}}$, Sandro G. Chiodo ${ }^{\mathrm{e}}$, Tzonka Mineva ${ }^{\mathrm{e}}$, \\ Julien Cardin ${ }^{\mathrm{f}}$, Svetlana Mintova ${ }^{\mathrm{b}, *}$ \\ a State Key Laboratory on Integrated Optoelectronics, College of Electronic Science and Engineering, Jilin University, 130012, Changchun, China \\ ${ }^{\mathrm{b}}$ Laboratoire Catalyse \& Spectrochimie (LCS), University of Caen, CNRS, 6 boulevard du Maréchal Juin, 14050, Caen, France \\ ${ }^{c}$ CRISMAT, ENSICAEN, University of Caen, 6 boulevard Maréchal Juin, 14050, Caen, France \\ ${ }^{\mathrm{d}}$ Laboratoire de Spectrochimie Infrarouge et Raman (LASIR), CNRS, University of Lille I, 59655, Villeneuve d'Ascq Cedex, France \\ e Institut Charles Gerhardt Montpellier, CNRS/ENSCM/UM1/UM2, 8 rue de l'Ecole normale, 34296, Montpellier, France \\ ${ }^{\mathrm{f}}$ Centre de Recherche sur les Ions, les Matériaux et la Photonique (CIMAP), ENSICAEN, UMR 6252 CNRS, CEA/IRAMIS, University of Caen, 6 boulevard \\ Maréchal Juin, 14050, Caen, France
}

Keywords:

Nanosized zeolite

EMT

Luminescent silver clusters

Emission properties

\begin{abstract}
A B S T R A C T
Stable luminescent silver clusters in nanosized EMT zeolite suspension were prepared and directly observed with high-resolution transmission electron microscopy (HRTEM). The luminescence of the Ag clusters remains stable in time due to their stabilization within the sodalite cages $(0.7 \mathrm{~nm})$ of the EMT zeolite nanocrystals. In addition to the experimental results, the first principle Density Functional Theory (DFT) computations showed that hydrated neutral clusters up to octamer $\left(\mathrm{Ag}_{8}\right)$ with a diameter of $0.47 \mathrm{~nm}$ were stabilized in the sodalite cages of the EMT zeolite, trough binding of silver atom(s) to the zeolite oxygen(s). The silver clusters exhibit molecular-like emission properties $\left(\mathrm{l}_{\mathrm{em}}=395 \mathrm{~nm}\right.$ and $\mathrm{t}_{1}$ / $2 \leq 1 \mathrm{~ns}$ ) that are in a good agreement with the HRTEM and DFT results. The stabilization of charge silver species in the form of weakly interacting dimer or trimer was observed too, which was based on the microsecond lifetime of the emission band measured at $545 \mathrm{~nm}$. The high stability combined with the luminescence properties of silver clusters in the EMT zeolite nanocrystals will be of great advantage for applications such as bio imaging and bio sensing.
\end{abstract}

\section{Introduction}

The potential use of sub-nanometer sized noble metal clusters in photoluminescence based applications like imaging, sensing, emission sensitizer or as bright-light emitting device has been reported [1-3]. The unique optical properties of these oligomeric clusters with size bellow the Fermi wavelength $(0.5 \mathrm{~nm})$ constituted by a few number of atoms, which are governed by their molecular-like electronic structures. They exhibit discrete states with energy level spacing larger than the thermal activation energy $\mathrm{k}_{\mathrm{B}} \mathrm{T}$ [4-6]. For comparison, larger metal nanoparticles possess a band structure with higher density of states with energy-level spacing smaller than the thermal activation energy. Therefore large metal nanoparticles (NPs) are usually not directly emissive,

\footnotetext{
* Corresponding author.

E-mail address: svetlana.mintova@ensicaen.fr (S. Mintova).
}

but they can enhance or sensitize the luminescence properties of an emitting center located in their vicinity by a plasmonic type response.

Photoluminescence from silver, copper, or gold oligomers have been reported earlier with emission properties that strongly depend on the size and shape of the cluster, and on the surface interactions $[5,6]$. Therefore the focus now is on the elaboration of synthesis routes for fine tuning of the emissive properties of the metal clusters. Chemical bottom-up approaches are the most suitable for large-scale materials production. Most of them consist of one (or several) reduction step of a cationic (or oxidized) precursor, followed by the limitation of coalescence/aggregation processes.

Different strategies for preparation of silver clusters are developed including: (i) the capping of silver surface with a protective monolayer [7], (ii) the preparation silver with various scaffolds, such as DNA [8], polyphosphates [9], peptides [10], and polymers [11], and (iii) the incorporation of silver within solid matrix 
containing pores with a size of the cluster dimension [12-14]. Among solid matrix, zeolites, owing to their ordered crystalline structures of sub-nanometer sized channels and cages, and to their ion-exchange capacity, are recognized for long time as materials of choice for stabilization of metal clusters. It was notably demonstrated that the negative charge of the lattice and the coordinating properties of the lattice oxygen atoms can stabilize both the metal cations and the unstable intermediates during the reduction processes [15]. Recent progress in controlling the metal aggregation was obtained by using nanosized zeolites as host materials. Probably due to the shortest diffusion length through the nanocrystals, the synthesis of copper, silver, palladium or platinum using radiolysis or chemical reduction methods in colloidal suspension often results in the stabilization of extremely small metal nanoparticles with a size close to the nanometer. Notably, in the GIS type zeolite stable copper clusters were successfully prepared [16]. Similar results were also obtained by studying the formation of $\mathrm{CdS}$ nanoparticles in LTL zeolite nanocrystals [17]. These previous works suggest that the controlled formation of small metal oligomers hosted in nanosized zeolites can be achieved.

So far, among the metal clusters within various type zeolites, the silver clusters attracted more and more attentions and the luminescent property of $\mathrm{Ag}$ activated zeolites was mostly intensively studied, while, the exact luminescence mechanism is still under debate till now. Among the explanations, the sub-nm scale molecule-like Ag clusters complying with the quantum confinement effect within the zeolite matrix is most proposed. For example, the $\mathrm{Ag}$ activated zeolite often exhibits yellow-green emission at $530-590 \mathrm{~nm}$, which is tentatively attributed to the linear $\mathrm{Ag}_{3}^{+}$clusters [18]. Also, $\mathrm{Ag}_{2}^{\mathrm{n}+}, \mathrm{Ag}_{3}^{\mathrm{n}+}, \mathrm{Ag}_{4}^{\mathrm{n}+}$ and $\mathrm{Ag}_{8}^{\mathrm{n}+}$ clusters were found in FAU frameworks, and $\mathrm{Ag}_{3}^{\mathrm{n}+}$ and $\mathrm{Ag}_{6}^{\mathrm{n}+}$ clusters were frequently identified in LTA frameworks [18] with different optical properties. Besides, the investigation of the growing process of silver nanoparticles in BEA nanosized zeolite revealed that silver clusters $\left(\mathrm{Ag}_{2}^{+}, \mathrm{Ag}_{3}^{2+}\right.$ and $\left.\mathrm{Ag}_{4}^{2+}\right)$ are transiently present in the course of the nanoparticles coalescence [19]. Recently, O. Fenwick et al. reported that the optical properties of silver clusters confined in zeolites depend on the size and geometry of the confined space as well as on metal-host electrostatic interactions by studying the ionization potential [20]. By fine-tuning of the zeolite host environment, they demonstrate very high photoluminescence quantum yields. However, these important results needs further confirmation, because the quantum confinement is difficult to explain since no obvious gaps or "walls" were observed in the silver loaded zeolite matrix that prevents the electron migration. In addition, the preparation of metal clusters in zeolites often terminates with the stabilization of larger metal nanoparticles on the external surface of the zeolite crystals.

The present work reports on the preparation of silver clusters composted of several atoms in nanosized EMT type zeolite stabilized in water suspensions with main emphasis on their photoluminescence properties. The three dimensional EMT type zeolite is built from sodalite cages (or $\beta$-cages) linked through double 6 -rings (D6Rs) into the hexagonal faujasite layers. The EMT type zeolite features a supercage (with a volume of $1.15 \mathrm{~nm}^{3}$ ), a hypocage $\left(0.61 \mathrm{~nm}^{3}\right)$ and a hypercage $\left(1.24 \mathrm{~nm}^{3}\right)[21]$. The stabilized Ag NPs in the EMT zeolite cages may have an electronic structure with discrete electronic energy levels with inter-levels energy gap larger than the thermal activation energy. Therefore, they are susceptible of exhibiting a fluorescence property, which could be tuned by systematical change of the silver loading and aggregation state, depending on the reducing environment. In particular, we explore the position of the Ag clusters and the growth evolution inside the confined cages. The nanosized zeolites can be stabilized in suspensions, which is favorable for monitoring the cluster formation inside the pores of the zeolite.

\section{Experimental section}

\subsection{Preparation of materials}

A template-free $\mathrm{Na}_{2} \mathrm{O}-\mathrm{Al}_{2} \mathrm{O}_{3}-\mathrm{SiO}_{2}-\mathrm{H}_{2} \mathrm{O}$ precursor system was employed for the preparation of the nanosized EMT type zeolite as follows: solution A was prepared by dissolving $9.074 \mathrm{~g}$ of sodium aluminate (Strem Chemicals, $56.2 \% \mathrm{Al}_{2} \mathrm{O}_{3}, 39.5 \% \mathrm{Na}_{2} \mathrm{O}$ ) and $1.61 \mathrm{~g}$ of sodium hydroxide (Prolabo, 97\%) in $100 \mathrm{~g}$ of distilled water followed by mixing with $44.00 \mathrm{~g}$ of sodium hydroxide to give a clear suspension; solution B was prepared by adding $57.692 \mathrm{~g}$ of sodium silicate (Prolabo, $27 \% \mathrm{SiO}_{2}, 8 \% \mathrm{Na}_{2} \mathrm{O}$ ) and $20.00 \mathrm{~g}$ of sodium hydroxide in a $250 \mathrm{ml}$ bottle containing $80 \mathrm{~g}$ of distilled water, followed by stirring until the solution became completely transparent. Then, solution A was poured slowly into solution B under vigorously stirring. A clear suspension was formed with the following molar composition: $18.45 \mathrm{Na}_{2} \mathrm{O}: 1 \mathrm{Al}_{2} \mathrm{O}_{3}: 5.15 \mathrm{SiO}_{2}: 240 \mathrm{H}_{2} \mathrm{O}$. The suspension was continuously stirred for $5 \mathrm{~min}$, and then kept at $35{ }^{\circ} \mathrm{C}$ for $36 \mathrm{~h}$ until the crystallization process of nanosized EMT type zeolite was accomplished. The crystalline EMT zeolite sample was finally purified to $\mathrm{pH}=8$.

The ion exchange of EMT zeolite with silver was performed in the water suspension to avoid possible agglomeration during drying. The ion-exchange process was performed as follows: $20 \mathrm{ml}$ silver perchlorate solutions with a concentration of $0.05 \mathrm{M}$ were added to three EMT zeolite suspensions (solid concentration of $7.5 \mathrm{wt} \%, 12 \mathrm{ml}$ ) and kept for $2 \mathrm{~h}, 4 \mathrm{~h}$ and $6 \mathrm{~h}$. The ion-exchanged samples were purified three times via high-speed centrifugation and redispersed in water. The reduction of silver cations $\left(\mathrm{Ag}^{+}\right)$to silver clusters $\left(\mathrm{Ag}^{0}\right)$ in the EMT zeolite suspensions ( $2 \mathrm{wt} \%, 7 \mathrm{ml}$ ) were obtained under microwave reduction $\left(120{ }^{\circ} \mathrm{C}, 10 \mathrm{~min}\right.$, $1000 \mathrm{~W})$ in the presence of a triethylamine $\left(\mathrm{N}\left(\mathrm{C}_{2} \mathrm{H}_{5}\right)_{3}, 0.5 \mathrm{ml}, 2 \mathrm{ml}\right.$ and $4 \mathrm{ml}$ ) as a reducing agent [22]. The reduced suspensions were again purified three times and finally dispersed in water. For clarity, the samples with different ion exchange time ( $2 \mathrm{~h}, 4 \mathrm{~h}$ and $6 \mathrm{~h}$ ) and different amount of reducing agent $(0.5 \mathrm{ml}(0.5 \mathrm{~N}), 2 \mathrm{ml}(2 \mathrm{~N})$ and $4 \mathrm{ml}(4 \mathrm{~N})$ will be abbreviated as EMT-2h0.5 N, EMT-2h2N, EMT$2 \mathrm{~h} 4 \mathrm{~N}$, EMT-4h0.5 N, EMT-4h2N, EMT-4h4N, EMT-6h0.5 N, EMT6h2N and EMT-6h4N (Table 1).

\subsection{Characterization of materials}

The structure of the EMT zeolite and presence of silver was confirmed by recording the Powder X-ray Diffraction (XRD) patterns using a PANalytical X'Pert Pro diffractometer with $\mathrm{Cu} \mathrm{K} \alpha$ radiation $(\lambda=1.5418 \AA$ ). The XRD patterns were recorded in the $2 \theta$

Table 1

ICP results of silver containing EMT zeolite samples.

\begin{tabular}{llllll}
\hline Sample $^{\mathrm{a}}$ & $\mathrm{Ag}(\mathrm{wt} \%)$ & $\mathrm{Si}(\mathrm{wt} \%)$ & $\mathrm{Al}(\mathrm{wt} \%)$ & $\mathrm{Na}(\mathrm{wt} \%)$ & $\mathrm{Ag}$ atoms exchanged \\
\hline Pure EMT & 0 & 13.3 & 11.9 & 12.1 & 0 \\
EMT-2h0.5N & 9.2 & 13.4 & 11.9 & 6.3 & 6 \\
EMT-2h2N & 9.0 & 15.0 & 12.9 & 7.5 & 6 \\
EMT-2h4N & 10.0 & 13.3 & 12.9 & 7.5 & 6 \\
EMT-4h0.5N & 11.0 & 12.9 & 11.2 & 4.5 & 14 \\
EMT-4h2N & 11.1 & 11.5 & 10.5 & 3.9 & 14 \\
EMT-4h4N & 13.4 & 10.5 & 11.5 & 5.1 & 14 \\
EMT-6h0.5N & 18.0 & 11.2 & 10.7 & 2.2 & 22 \\
EMT-6h2N & 17.6 & 11.3 & 10.3 & 2.2 & 22 \\
EMT-6h4N & 17.4 & 9.5 & 9.5 & 2.7 & 22
\end{tabular}

a Samples are named by the ion exchange time ( $2 \mathrm{~h}, 4 \mathrm{~h}$ and $6 \mathrm{~h})$ and amount of reducing agent $(0.5 \mathrm{~N}, 2 \mathrm{~N}$ and $6 \mathrm{~N})$. 
range $4^{\circ}-80^{\circ}$, with a step size of $0.02^{\circ}$. The size and confined arrangements of silver within the zeolite nanocrystals were determined by high-resolution transmission electron microscopy (TEM) using a FEI Titan 80-300 operating at $300 \mathrm{kV}$. The chemical composition of the samples was measured on a Varian Vista AXCCD inductively coupled plasma atomic emission spectrometer (ICPAES). UV-VIS absorption spectra of the silver loaded zeolite suspensions were recorded using a Varian Cary 4000 Spectrophotometer. Photoluminescence spectra were recorded using a HoribaJobin-Yvon Spex Fluorolog Spectrofluorimeter.

Single-photon counting (SPC) measurements were performed using a Fluotime200 fluorescence lifetime spectrometer (PicoQuant) equipped with a MCP-PMT detector (R3809U-50, Hamamatsu). The fluorescence was excited at $280 \mathrm{~nm}$ by the 4 th harmonic of a Chameleon Ti:Sa laser (Coherent). The polarization between the laser pome and the emitted light was set to the magic angle $\left(54.7^{\circ}\right)$ in order to omit the contribution of the reorientation of molecules on the decay dynamics. The instrumental response function has a full width half maximum (FWHM) less than 50 ps.

\subsection{Computational details and models}

Computations based on the Density Functional Theory (DFT) methods were performed using deMon2k $[23,24]$ computer code. For the exchange-correlation functional Perdew-Burke-Ernzerhof's 1996 (PBE) exchange-correlation functional approximation was used [25]. Double-basis sets were employed for all atoms [26]. Automatically generated auxiliary functions up to $1=2$ were used for fitting the density [27]. QuasiNewton method in internal redundant coordinates with analytical energy gradients was used for the structure optimizations [28]. The convergence was based on the Cartesian gradient and displacement vectors with thresholds of $10^{-4}$ a.u.

To model the EMT type zeolite, a cluster containing a complete sodalite cage ( $\mathrm{Na}_{36} \mathrm{Al}_{36} \mathrm{Si}_{36} \mathrm{H}_{48} \mathrm{O}_{168}$ ), as shown in Fig. S1, Supporting Information (SI), was cut from the periodic crystallographic structure. For the calculations, the Si/Al ratio of 1.0 for the EMT type zeolite was considered. The neutrality of the bare zeolite cluster is maintained with insertion of sodium cations, initially placed at the crystallographic positions, reported for a Na-EMT zeolite with $\mathrm{Si} / \mathrm{Al}$ ratio of 3.31 and $\mathrm{Na} / \mathrm{Al}$ ratio of 0.949 [29]. The zeolite model was completely relaxed in order to establish the positions of sodium corresponding to the minimum energy configuration. Further, the sodium ions in the sodalite cage were exchanged with three, four, six, eight and fourteen $\mathrm{Ag}$ cations $\left(\mathrm{Ag}^{+}\right)$in order to model completely the reduced $\mathrm{Ag}$ cluster $\left(\mathrm{Ag}^{0}\right)$. Protons were inserted into the structures with silver clusters to compensate the negative charge resulting from the removal of the sodium cations. Structures with protons in the zeolite framework and on the silver clusters were considered too.

\section{Results and discussion}

\subsection{General characterization of materials}

Template-free EMT zeolite nanocrystals were prepared from sodium-rich $\mathrm{Na}_{2} \mathrm{O}-\mathrm{Al}_{2} \mathrm{O}_{3}-\mathrm{SiO}_{2}-\mathrm{H}_{2} \mathrm{O}$ precursor suspension and used for stabilization of $\mathrm{Ag}$ clusters [30]. After ion exchange of the EMT zeolite suspensions with silver perchlorate, the reduction process was performed under microwave treatment in the presence of the reducing agent $\left.\left(\mathrm{N}_{2} \mathrm{C}_{2} \mathrm{H}_{5}\right)_{3}\right)$. The chemical compositions of the samples are summarized in Table 1 . The silver concentration for samples subjected to ion exchange for $2 \mathrm{~h}, 4 \mathrm{~h}$, and $6 \mathrm{~h}$ is $9 \mathrm{wt} \%$, $12 \mathrm{wt} \%$, and $17 \mathrm{wt} \%$, respectively, according to the ICP chemical analysis. The corresponding numbers of silver cations per unit cell are 6,14 , and 22 , correspondingly. The ion-exchanged and reduced samples are crystalline as shown in the XRD patterns collected from purified samples (Fig. S2).

\subsection{UV-VIS spectra of silver containing zeolite suspensions}

UV-VIS absorption spectra of pure, silver ion-exchanged, and reduced silver containing EMT zeolite suspensions are depicted in Fig. 1 (a, b, c) with the corresponding images of the reduced samples (insets). The three series of samples, distinct from each other by their silver content (see Table 1 ), show qualitatively the same UV-VIS band evolution versus the amount of reducing agent. The pure EMT zeolite samples of each batch exhibit the typical shape associated with the scattering of the light from the zeolite crystals in the suspension. After ion exchange, a new peak at $212 \pm 2 \mathrm{~nm}$ with a shoulder around $230 \pm 3 \mathrm{~nm}$ in samples $\mathrm{Ag}^{+}$-EMT-2h, $\mathrm{Ag}^{+}-$ EMT-4h, and $\mathrm{Ag}^{+}$-EMT-6h is observed as the dashed lines and arrows point out. These bands are previously assigned to the $5 \mathrm{~s} \leftarrow 4 \mathrm{~d}$ transition of (i) $\mathrm{Ag}^{+}$isolated $(212 \mathrm{~nm})$ [31] or in electrostatic interaction with (ii) positively charged compounds $(230 \mathrm{~nm})$ as for example $\left(\mathrm{Ag}^{+}\right)_{3}$ trimers in zeolite, (iii) $\left(\mathrm{Ag}^{+}\right)_{2}$ in halide and phosphate glasses [32], or (iv) $\mathrm{Ag}^{+}$-polyacrylate acid complex in solutions [33]. The intensity of these bands decreases after the addition of the reducing agent $\left(\mathrm{N}\left(\mathrm{C}_{2} \mathrm{H}_{5}\right)_{3}\right)$ in the EMT zeolite suspensions but they do not disappear completely. The decay is more pronounced for the series of samples EMT-4h and EMT-6h (Fig. 1 b,c). In the presence of $\mathrm{N}\left(\mathrm{C}_{2} \mathrm{H}_{5}\right)_{3}$, a second broad band with weaker intensity extending over the region of $245-300 \mathrm{~nm}$ is detected. Its maximum shifts from $249 \mathrm{~nm}$ to $253 \mathrm{~nm}$ as the silver concentration increases in the ion-exchanged samples. The intensity of the latter band increases firstly with the amount of the reducing agent used, and secondly decreases as the reduction process further progresses. Absorption bellow $300 \mathrm{~nm}$ is usually a signature of few-atomcontaining silver clusters. For sample EMT-2h, this band $(249 \mathrm{~nm})$ is observed in the ion-exchanged form $\left(\mathrm{Ag}^{+}\right.$-EMT2h), and the intensity increases with increasing the $\mathrm{N}\left(\mathrm{C}_{2} \mathrm{H}_{5}\right)_{3}$ concentration (EMT$2 \mathrm{~h} 2 \mathrm{~N}$ ), and finally diminished for sample EMT-2h4N concomitantly with the appearance of the plasmon extinction band at $400 \mathrm{~nm}$. For the series of samples EMT-4h and EMT-6h, the bands at $251 \mathrm{~nm}$ and $253 \mathrm{~nm}$, respectively appear for the lowest concentration of reducing agent $(0.5 \mathrm{~N})$, and then disappear for the samples with higher concentration of reducing agent concomitantly with the appearance of the broad extinction band at $400 \mathrm{~nm}$. The color of the zeolite suspensions changed as well as shown Fig. 1 (insets). All zeolite suspensions are highly stable, and no sedimentation with time is observed. Sample EMT-4h4N exhibits an intense darkbrownish coloration resulting from the combination of the intense plasmon band of silver nanoparticles with the scattering from the highly concentrated zeolite suspension. It is worth noting that the EMT-6h0.5 N sample exhibits already at low concentration of $\mathrm{N}\left(\mathrm{C}_{2} \mathrm{H}_{5}\right)_{3}$ a deep orange coloration while no plasmon band is detected in the absorption spectrum. This is consistent with the formation of oligomeric charged silver clusters, $\mathrm{Ag}_{7}^{3+}$ for example, or smaller $\mathrm{Ag}_{\mathrm{n}}$ clusters $(\mathrm{n}>5)$ that are known to exhibit a large absorption band over the visible spectral range. In comparison, samples EMT-4h0.5 N and EMT-2h0.5 N have a pale whitish color suggesting that only very small oligomers are formed $\operatorname{Ag}_{n}(n<4)$. While the EMT-2h4N exhibits a pale yellow coloration reflecting the formation of larger clusters absorbing in the range 300-400 nm, where $\mathrm{Ag}_{4}^{2+}$ are usually detected [33].

The three samples (EMT-2h4N EMT-4h4N EMT-6h4N) with the highest content of reducing agent are colored, but the different colorations assess the formation of silver clusters with different size distributions. From the UV-VIS absorption data one can conclude that by well-defined and controlled tuning of the concentration of 

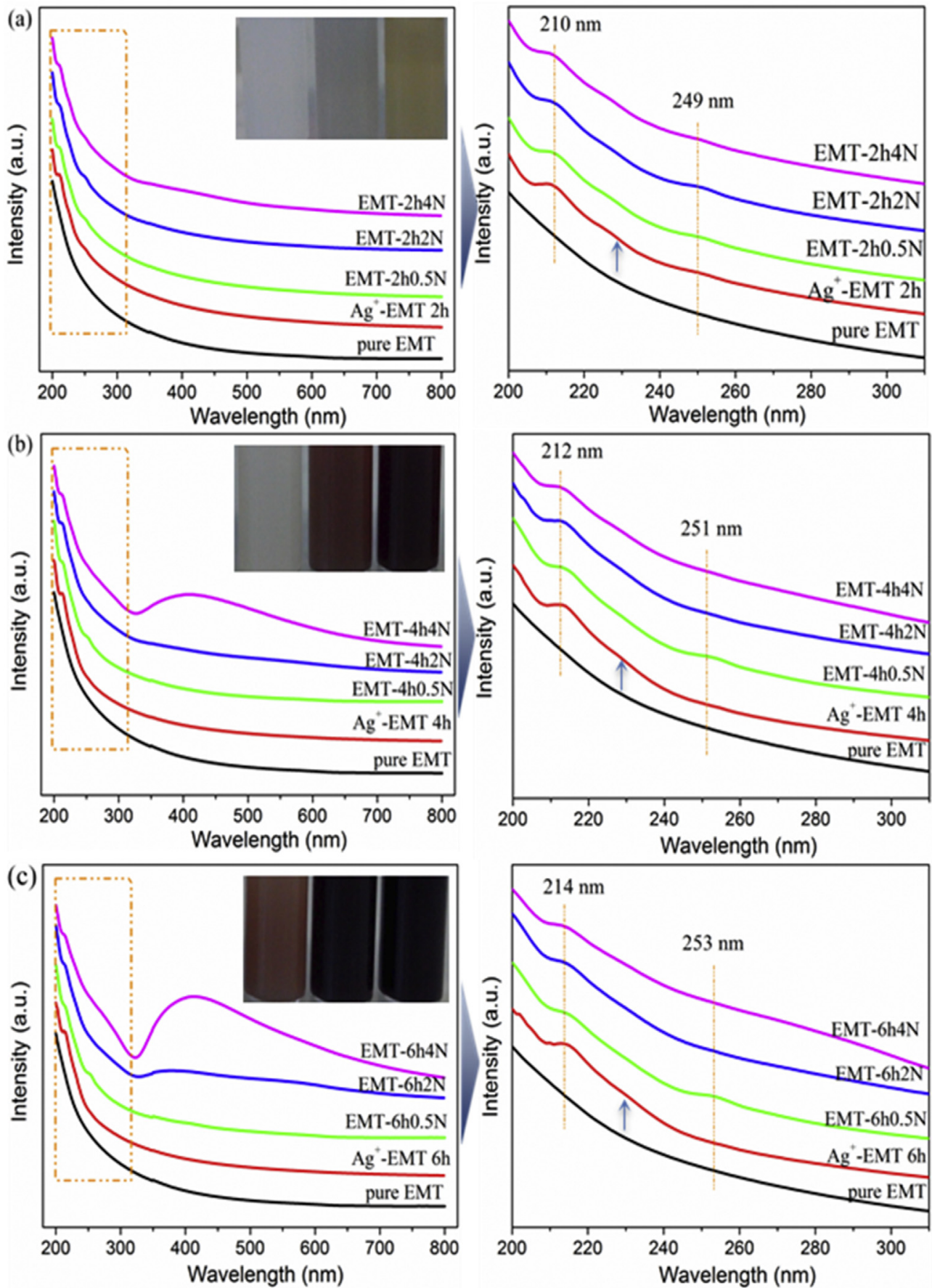

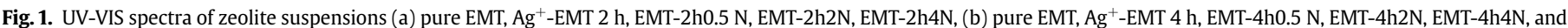

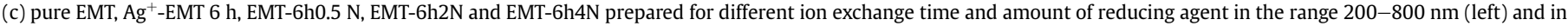
the range 200-300 nm (right). Inset: pictures of the corresponding reduced zeolite suspensions (constant zeolite concentration of $10 \mathrm{mg} / \mathrm{ml}$ ).

silver and reducing agent in the EMT zeolite suspension, silver clusters can be readily prepared with a size ranging from few atoms structures with molecular-like electronic band structure to larger metallic nanoparticles with metal-like electronic band structure.

\subsection{Size and distribution of silver clusters in zeolite suspensions}

Further the crystallinity and location of silver in the zeolite EMT2h2N, EMT-4h2N and EMT-6h2N suspensions is studied by HRTEM (Fig. 2 and Fig. S3).
As shown (Fig. 2), both the size and amount of silver cluster increase with increasing the silver concentration $(9 \%, 12 \%$ and $17 \%$ for samples EMT-2h2N, EMT-4h2N and EMT-6h2N, respectively). In case of sample EMT-2h2N, black spots of extremely small size $(0.5-0.7 \mathrm{~nm})$ inside the sodalite cages of the EMT nanocrystals are exclusively detected (red arrows).

As the initial silver content increases (sample EMT-4h2N) the amount of black spot increases but remains of sub-nanometer size (smaller than $0.7 \mathrm{~nm}$ ) and they are predominantly located in the sodalite cages (size of $0.7 \mathrm{~nm}$ ) of the EMT zeolite. For the sample 

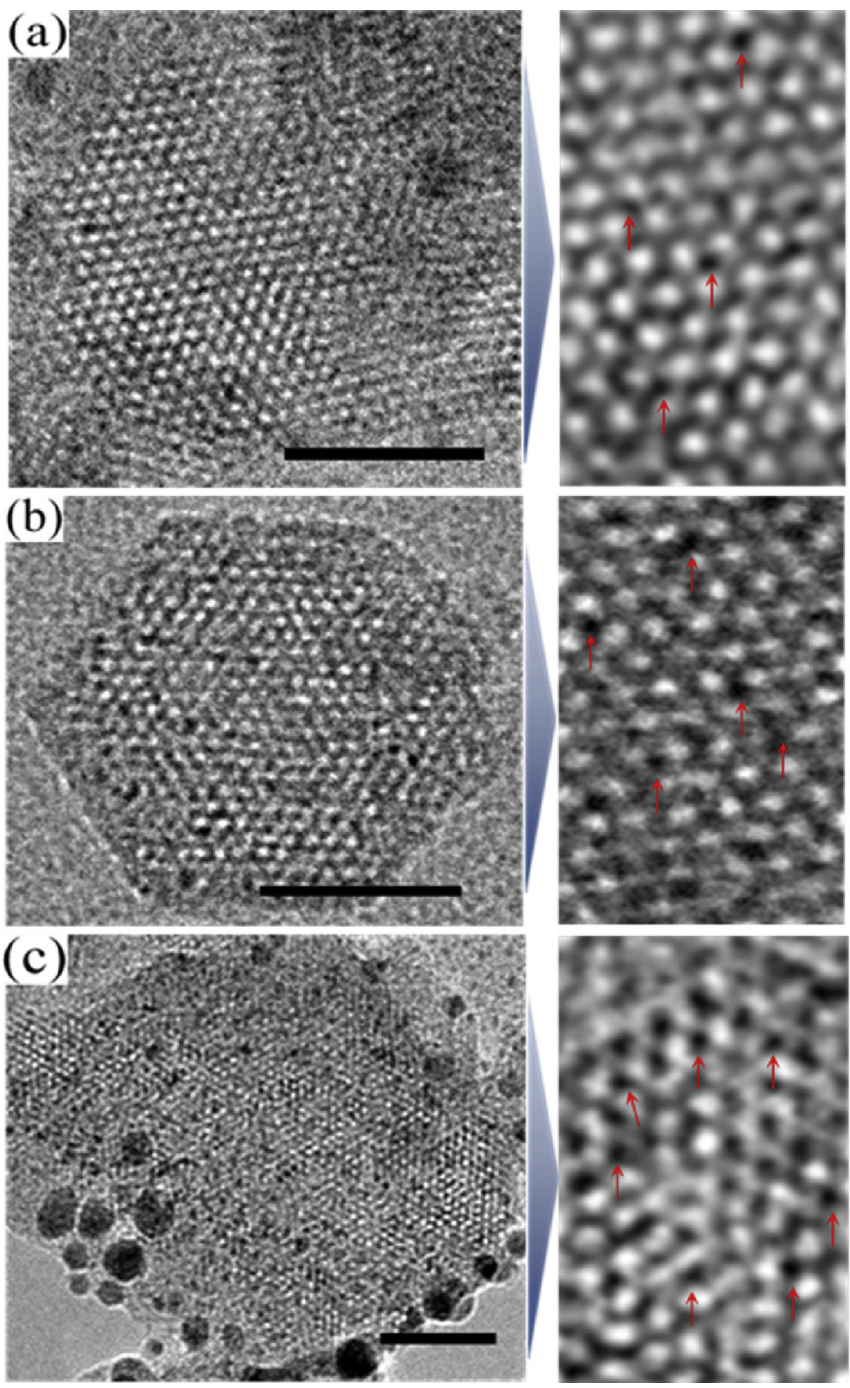

Fig. 2. HRTEM pictures of EMT zeolite crystals from suspensions (a) EMT-2h2N, (b) EMT-4h2N, and (c) EMT-6h2N. Scale bar: $M=20 \mathrm{~nm}$.

with the highest silver content (EMT-6h2N), larger silver nanoparticles at the surface of the EMT nanocrystals are detected (Fig. 2c) and their size is less than $3 \mathrm{~nm}$. Moreover, the zeolite nanocrystals are completely preserved, i.e., both the supercages and sodalite cages are well seen in the HRTEM pictures recorded for all samples (Figs. 2 and 3). Schematic diagram of the EMT framework structure overlapping with the HRTEM image (experimental unit cell of $17.42 \AA$ ) match well with the corresponding value of the theoretical unit cell calculated for pure silica zeolite (17.45 $\AA$ ) (Fig. 3). This further confirms that the silver clusters (black dots) stay singly and intact in the sodalite cages of the EMT zeolite nanocrystals. Further increase of the exposure time of the sample to the e-beam results in new black dots that appear in the EMT supercages (Fig. 3b). Although the $\mathrm{Ag}^{+}$in the sodalite cages are successfully reduced to silver clusters $\left(\mathrm{Ag}^{0}\right)$ during the microwave treatment of the zeolite suspensions, still some $\mathrm{Ag}^{+}$in the EMT supercages are be further reduced by the electron beam during the TEM measurements. The silver cations may migrate from the sodalite cages and contribute to the formation of $\mathrm{Ag}$ clusters in the supercages too, indicating that the formation of silver clusters inside the supercage can be realized in the presence of high amount of reducing agent. This stage is last prior the formation of silver nanoparticles on the external surface of the zeolite, as shown in Fig. 2. In summary, three stages can be identified during the reduction process of silver containing zeolite suspensions: (i) the formation of silver clusters inside the sodalite cages of EMT zeolite, (ii) the formation and migration of silver clusters inside the supercage of EMT zeolite, and (iii) the formation of larger silver metallic nanoparticles on the external surface of the EMT zeolite crystals. The silver species in the EMT-4h4N, EMT-6h2N and EMT$6 \mathrm{~h} 4 \mathrm{~N}$ samples during the latest stage of reduction are obviously metal nanoparticles that exhibit the typical plasmon band at $410 \mathrm{~nm}$. The absorption at $251 \mathrm{~nm}$ appears in nearly all samples and must be assigned to silver oligomers that do not possess a metallic character, but feature absorption bands of a cluster (Fig. 1). Similar absorption band was assigned to oxidized $\mathrm{Ag}_{\mathrm{m}}^{\mathrm{n}+}$ clusters in silver containing systems including $\mathrm{Ag} / \mathrm{Al}_{2} \mathrm{O}_{3}$ [34] and $\mathrm{Ag}-\mathrm{ZSM}-5$ [35]. The exact nature of these species are not identified yet but may correspond to larger clusters since their absorption band disappear under prolonged reduction.

\subsection{Computational results}

The DFT calculations show that completely reduced $\operatorname{Ag}_{n}(\mathrm{n}=3$, $4,6,8)$ structures can be stabilized in the sodalite cages of the EMT type zeolite due to binding of one or several silver atoms(s) with oxygen(s) from the zeolite framework. The $\mathrm{Ag}-\mathrm{O}$ bonds (length of 2.3-2.6 $\AA$ ) are formed by overlapping between Ag5s and 02p orbitals as established from the analysis of the molecular orbital compositions. Hydration of the Ag clusters favors additionally the $\mathrm{Ag}_{\mathrm{n}}$ stability as exemplified in Fig. 4 for the $\mathrm{Ag}_{4}$ structures.

Binding of the silver clusters to oxygen is the primary reason for the significant structural deformations of the clusters obtained, in comparison to their gas-phase analogues [36]. The energetically most favored $\mathrm{Ag}_{4}$ (Fig. 4a), and $\mathrm{Ag}_{6}$ (Fig. S4) oligomers in the sodalite cages differ mostly from their gas-phase planar rhombohedral $\left(\mathrm{Ag}_{4}\right)$ and triangular $\left(\mathrm{Ag}_{6}\right)$ topologies. Both structures are characterized with elongated $\mathrm{Ag}-\mathrm{Ag}$ bonds of $3.6-3.8 \AA$ in comparison to the isolated structures with averaged bonds of 3.2-3.5 $\mathrm{A}$. The $\mathrm{Ag}_{8}$ cluster (Fig. S4) with a geometrical diameter of $0.47 \mathrm{~nm}$, and bi-pyramidal shape is the most easily formed in the sodalite cages of the EMT zeolite, because only little geometrical distortions compared to the gas-phase $\mathrm{Ag}_{8}$ structure are observed. Indeed, the topology and $\mathrm{Ag}-\mathrm{Ag}$ bonds ( 3.16 and $3.47 \AA$ ) in $\mathrm{Ag}_{8}$ remain very similar to that of its gas-phase counterparts.

Besides, the formation energies of the silver clusters are computed considering the following reduction reaction: EMT $(\mathrm{nNa})+\mathrm{nAg}^{+}+$ $(\mathrm{n} / 4) \mathrm{N}_{2} \mathrm{H}_{4} \rightarrow \mathrm{Ag}_{\mathrm{n}} /$ EMT $(\mathrm{nH})+(\mathrm{n} / 4) \mathrm{N}_{2}+\mathrm{nNa}^{+}$(Table S1). Based on these results, we suggest that only hydrated forms of the completely reduced silver oligomers can be stabilized in the sodalite cage, and also giving preferences to structures with four and eight atoms. Thus, in the presence of neutral silver clusters protons would preferably bind to $A g_{n}$ than to the zeolite framework. Presumable existence of two Ag trimers or larger than 8 atomic clusters was ruled out by our computational results. During the geometry optimization, the two considered silver trimers resulted in a six-atomic oligomer. Moreover, the $\mathrm{Ag}_{14}$ cluster breaks down into an intact cluster with eight silver atoms and with six hydrogenated atoms migrating outside the sodalite cage, and three of them through the channel connecting the sodalite cavities. This result supports the conclusion that the maximum size of a neutral Ag clusters in the sodalite cage contains eight atoms and it is most likely hydrated.

\subsection{Emission spectra of silver containing zeolite suspensions}

More intriguing properties of the Ag clusters stabilized in the sodalite cages of EMT zeolite are revealed by recording the 

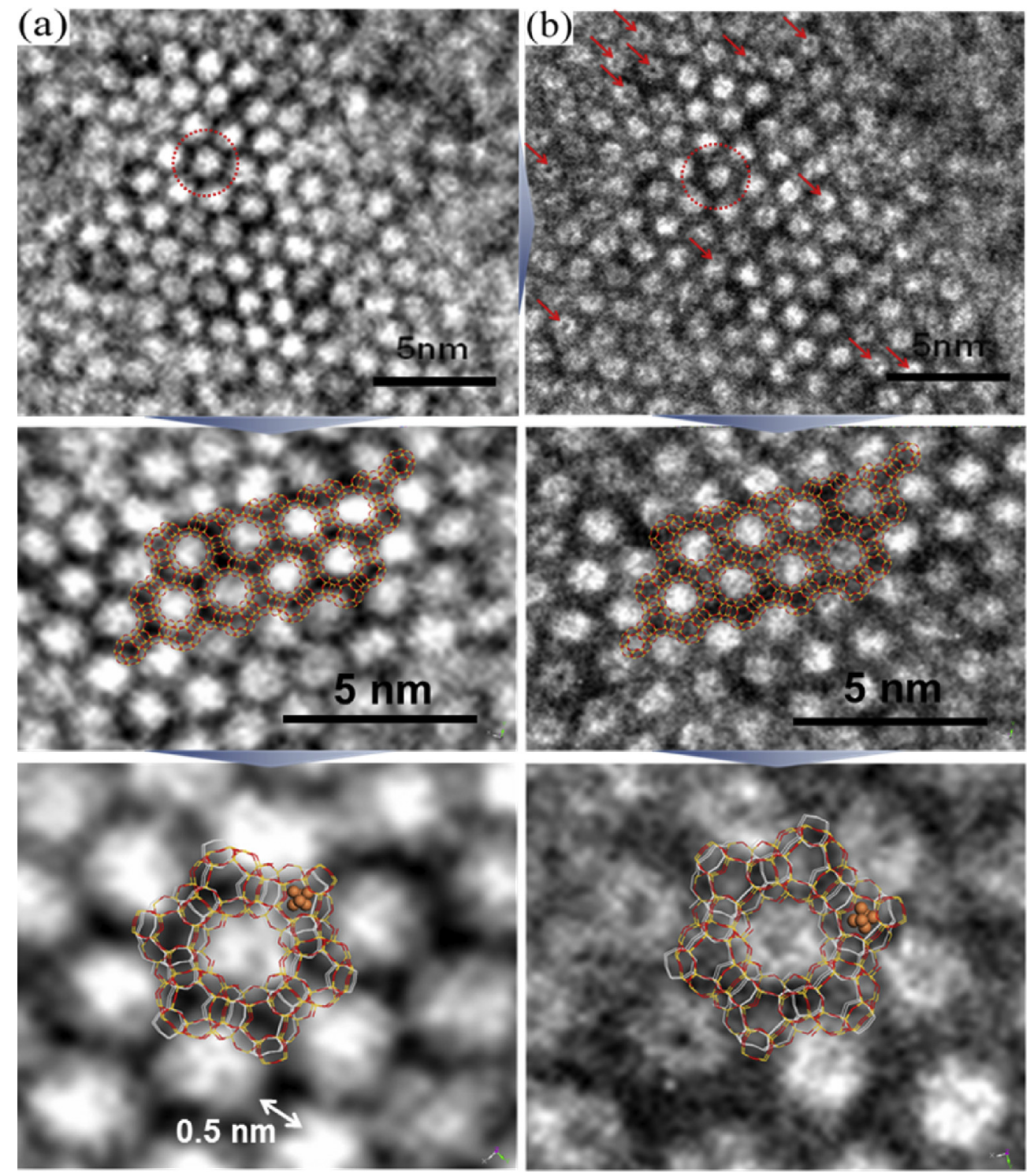

Fig. 3. HRTEM pictures of EMT zeolite crystals from suspension EMT-4h0.5 N, and the corresponding schematic diagram of the EMT framework structure after exposure under the e-beam for (a) 30 and (b) $90 \mathrm{~s}$. Red circle show the change in the same area of a single EMT crystal under exposure to electron beam for (a) $30 \mathrm{~s}$ and (b) $90 \mathrm{~s}$; the individual silver clusters are connected (fused) after $90 \mathrm{~s}$ continuous reduction under the beam. The red arrows point out the silver nanoparticles formed in the supercage of EMT zeolite crystals under long exposure time. (For interpretation of the references to colour in this figure legend, the reader is referred to the web version of this article.)

photoluminescence (PL) emission spectra (Figs. 5 and 6). Pure EMT and ion exchanged zeolite suspensions are non-emissive upon UV photoexcitation at $280 \mathrm{~nm}$. While all reduced suspensions exhibit two PL emission bands, a relatively sharp one centered at $395 \mathrm{~nm}$ (band I) and a second one with maximum at $545 \pm 10 \mathrm{~nm}$ (band II); the position and shape vary within the samples (Fig. 5).

The increase of silver content in the zeolite suspensions at the same reducing condition favors the formation of larger clusters resulting in subsequent increase of intensity of the emission band at $545 \mathrm{~nm}$ (sample EMT-4h2N). However, the EMT-6h2N sample with higher silver content has two emission bands with lower intensity. The luminescent spectra for samples EMT-4h0.5 N, EMT$4 \mathrm{~h} 2 \mathrm{~N}$ and EMT-4h4N with the same concentration of zeolite crystals and silver were recorded too. The spectra contain the two emission bands at $395 \mathrm{~nm}$ (band I) and $545 \mathrm{~nm}$ (band II) upon excitation at $280 \mathrm{~nm}$ (Fig. 6), and the intensity of these bands decreased in the EMT-4h4N sample. This can be explained with the formation of metallic silver nanoparticles in the latest sample, which are non-emitting. While the photoluminence for samples EMT-4h0.5 N, EMT-4h2N is assigned to small silver clusters, which is in a good agreement with the UV-VIS and HRTEM observations. Similar emission behavior of silver in glass materials was observed earlier $[37,38]$.

The spectra recorded for pure and ion-exchanged EMT samples are similar (Fig. S5), and they contain a broad band, which decreases from $350 \mathrm{~nm}$ to $545 \mathrm{~nm}$ that may be due to the light scattering from the zeolite crystals in the suspensions (as mentioned in the UV-VIS part, Fig. 1). The PL emission was recorded upon excitation at 250, 280 and $320 \mathrm{~nm}$ for samples EMT-4h0.5 N and EMT-4h2N (Fig. S6). The intensity of the emission excited at $250 \mathrm{~nm}$ remains negligible despite of the absorption band measured at this wavelength in UV-VIS (Fig. 1). Comparable and higher emission intensity is measured at $280 \mathrm{~nm}$ and $320 \mathrm{~nm}$ excitation wavelengths. The position of band I remains unchanged at different excitation wavelengths, while the relative intensity and position of band II are modified. Similar results are obtained for 

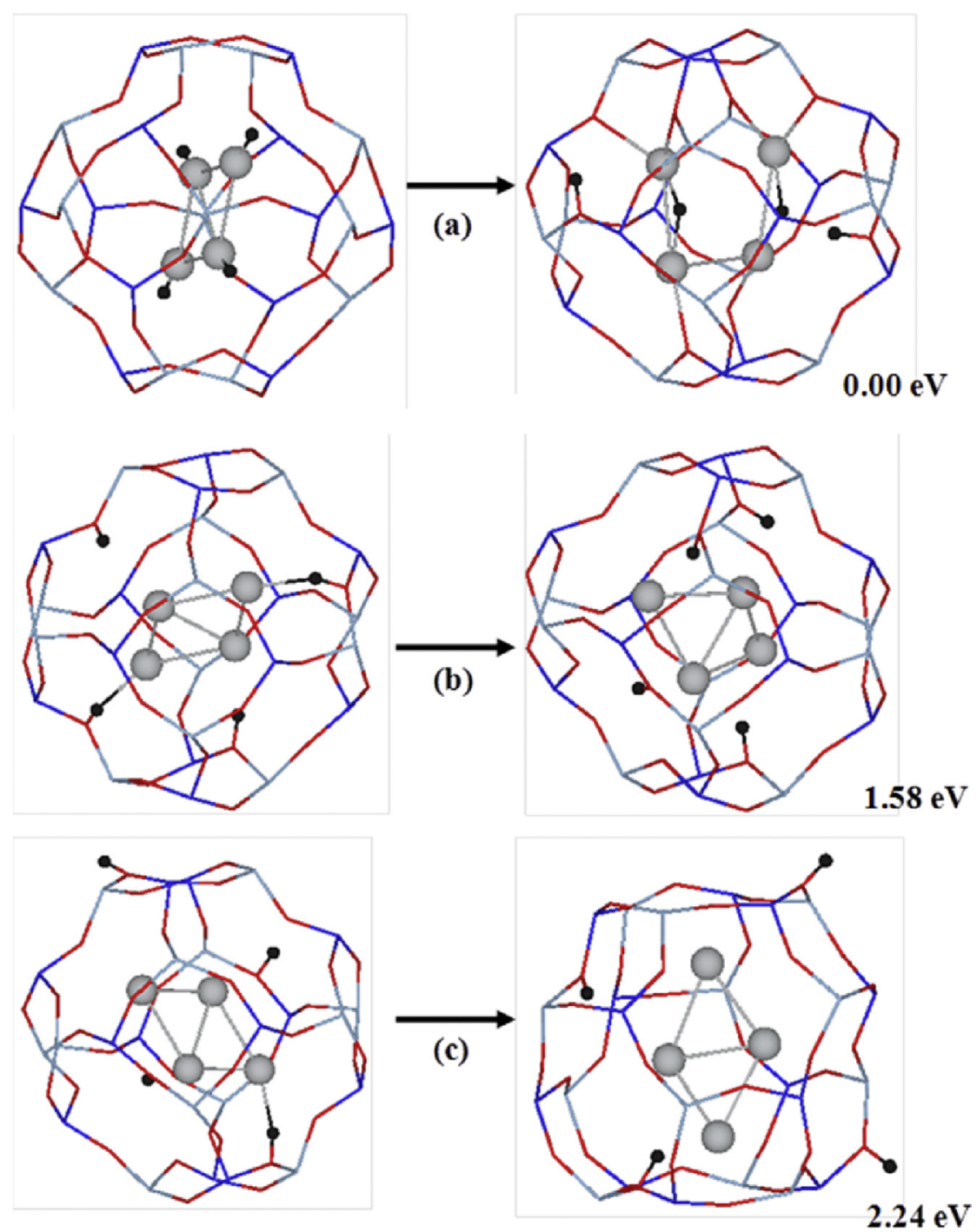

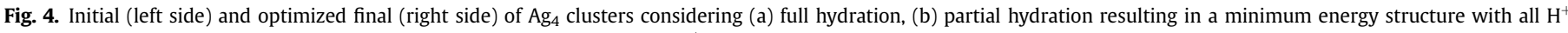

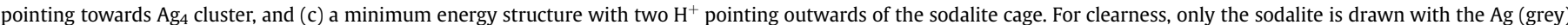

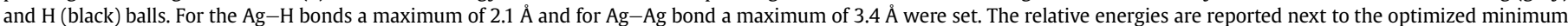
energy structures.

samples (EMT-2h0.5 N, EMT-2h2N, EMT-2h4N, EMT-6h0.5 N, EMT$6 \mathrm{~h} 2 \mathrm{~N}$, and EMT-6h4N) (Fig. S5), but it must be emphasized that in case of sample EMT-2h0.5 N, the intensity of band II is weaker.

The luminescence upon UV excitation of silver containing EMT suspensions in the spectral range $250-300 \mathrm{~nm}$ reveals a remarkable dual emission whose characteristics are determined by the degree of ion exchange and by the reducing condition. The luminescence disappears with the formation of larger silver nanoparticles and must therefore be associated with the presence of small oligomeric species. Based on the change in the relative intensity of band I $v s$. band II by changing the amount of silver or the reducing condition, these two bands must be assigned to emitting clusters with different sizes.

\subsection{Nature and lifetime of emitting silver clusters}

Identification of the nature of the emitting silver clusters in the EMT zeolite cannot be completed based on the single steady state UV-VIS data. Therefore, emission decay time measurements were performed by single photon counting technique to determine the lifetime and the nature of the emitting clusters responsible for the emissions (bands I at $395 \mathrm{~nm}$ and band II at $545 \mathrm{~nm}$ ). These experiments were carried out with the most luminescent sample EMT-4h. The decay of the luminescence upon excitation at $280 \mathrm{~nm}$ of pure EMT, EMT-4h0.5 N and EMT-4h4N is recorded at $395 \mathrm{~nm}$ (band I) and $545 \mathrm{~nm}$ (band II) and depicted in Fig. 7a and b, respectively.

For pure EMT suspension no luminescence is detected apart of the Instrumental Response Function (IRF). While for sample EMT$4 \mathrm{~h} 0.5 \mathrm{~N}$, the luminescence decay of the band I (395 nm) is multiexponential with an average lifetime $t_{1 / 2}-1$ ns. For sample EMT$4 \mathrm{~h} 4 \mathrm{~N}$, the emission decay exhibits shorter lifetime of $t_{1 /}$ $2^{-0.6}$ ns (Fig. 7a). Based on the strong intensity and fast decay time, the emission band I must correspond to a spin-allowed optical transition, and thus the band I may be assigned to the emission from small neutral molecular-like silver clusters stabilized in the sodalite cages of the EMT zeolite. For both samples (EMT-4h0.5 N and EMT-4h4N), the decay is multi-exponential that suggest cluster size or microenvironment distribution. The change in the emission lifetime observed for samples EMT-4H0.5 N and EMT-4N4H is in 


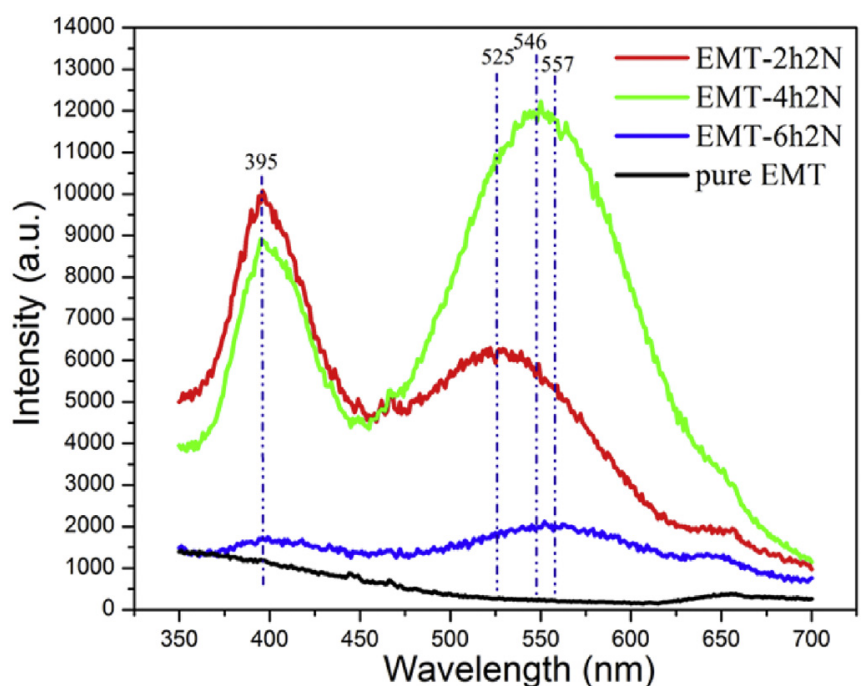

Fig. 5. Luminescence spectra of pure EMT, EMT-2h2N, EMT-4h2N and EMT-6h2N suspensions (excitation at $280 \mathrm{~nm}$ ).

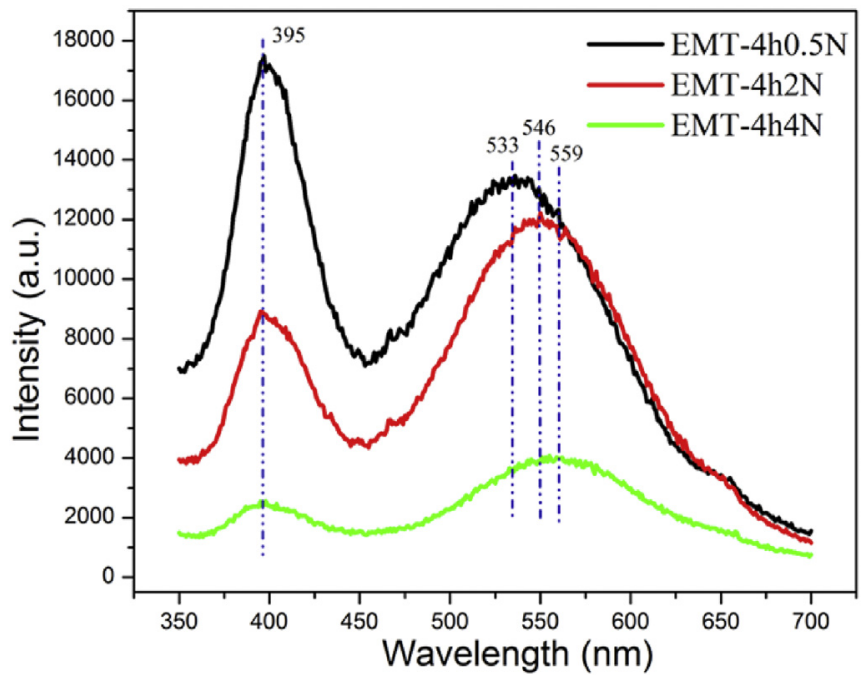

Fig. 6. Luminescence spectra of zeolite suspensions EMT-4h0.5 N, EMT-4h2N, and EMT-4h4N (excitation at $280 \mathrm{~nm}$ )

good agreement with the HRTEM data that reveal the silver migration from the sodalite cages $(0.7 \mathrm{~nm})$ to the supercages $(1.15 \mathrm{~nm})$ of the EMT zeolite crystals.

The emission of band II $(545 \mathrm{~nm})$ shows clearly different behavior. At this wavelength the time evolution of the emission consist in a fast component $\left(\mathrm{t}_{1 / 2}-3 \mathrm{~ns}\right)$ with small amplitude superimposed on a long-live decay $(\mathrm{t}>1 \mu \mathrm{s})$, which contribute to the most important part of the emission at this wavelength. The decay profile is not changing for samples EMT-4H0.5 N and EMT$4 \mathrm{H} 4 \mathrm{~N}$. The emission properties similar to the ones observed for band II were already assigned to the emission of $\mathrm{Ag}^{0}$ in a weak interaction with silver cations $[39,40]$ or to $\mathrm{Ag}_{3}^{+}$(fast decay component associated with a spin-allowed optical transition) and $\mathrm{Ag}_{6}^{+} / \mathrm{Ag}_{6}^{2+}$ (slow decay component associated with a spin-forbidden optical transition $[18,41]$. Therefore the second emission band (band II) is certainly due to charge silver species, however, additional investigations to clarify the exact nature of the emitting species are needed.
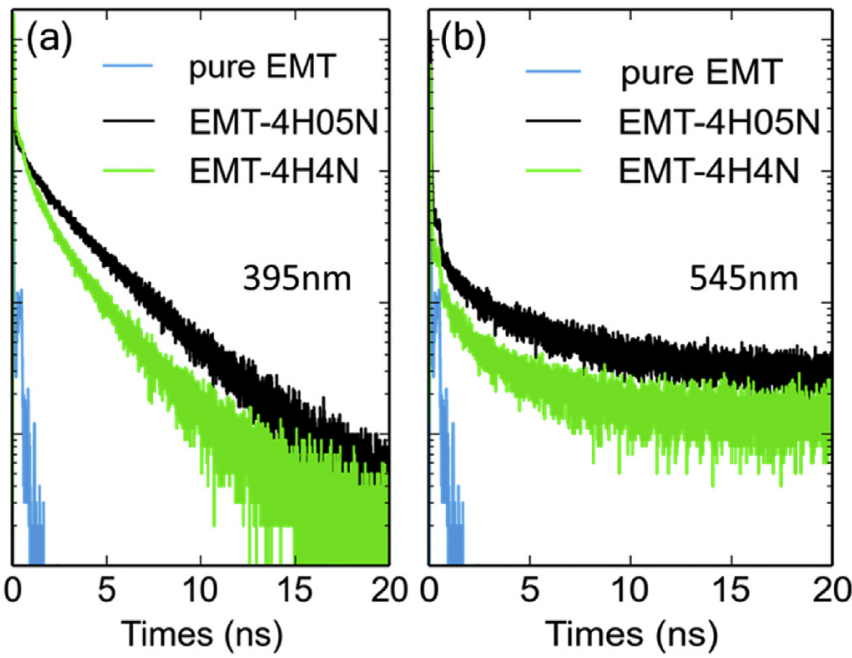

Fig. 7. Emission decay time measurements of zeolite suspensions (a) EMT-4h05 N and (b) EMT-4h4N recorded at $395 \mathrm{~nm}$ and $545 \mathrm{~nm}$ emission band; IRF- Instrumental Response Function excitation at $280 \mathrm{~nm}$.

\section{Conclusions}

The stabilization of silver clusters in nanosized EMT zeolite suspensions via ion exchange and microwave reduction is presented. The location of the silver clusters in the sodalite cages and super cages of the EMT zeolites is determined by HRTEM; the size of the silver clusters is controlled by adjusting the amount of reducing agent in connection with the amount of silver introduced in the EMT zeolite nanocrystals. The silver clusters have size of $0.5-0.7 \mathrm{~nm}$, which is clearly seen by HRTEM and this result is in a good agreement with the DFT calculations predicting hydrated $\mathrm{Ag}_{8}$ with a diameter of $0.47 \mathrm{~nm}$. The $\mathrm{Ag}_{8}$ clusters are among the most stable in the sodalite cages with geometrical characteristics allowing the cluster to bind to oxygen atoms without a distortion of the $\mathrm{Ag}_{8}$ gas-phase topology. Smaller hydrated clusters with similar energy stability ( $n \geq 4$ ) can also be formed.

The luminescence of $\mathrm{Ag}$ clusters is attributed to the formation of two types of emitting species. The emission band at $395 \mathrm{~nm}$, with a fast nanosecond decay time is assigned to the $\mathrm{Ag}_{8}$ clusters predicted also by the DFT calculation. The second emission band is probably due to $\mathrm{Ag}^{0}$ atoms weakly interacting with $\mathrm{Ag}^{+}$cations. Due to the stabilization of the silver clusters within the sodalite cages in the EMT zeolite, the luminescence properties are very stable with time. The high stability and excellent fluorescent properties of the Ag clusters in the EMT zeolite suspensions are likely to find extensive applications in bio imaging, chemical, and bio sensing.

\section{Author contributions}

The manuscript was written through contributions of all authors. All authors have given approval to the final version of the manuscript.

\section{Acknowledgements}

The financial support from the ANR "TAR-G-ED" and FFCSA is acknowledged. 


\section{Appendix A. Supplementary data}

Supplementary data related to this article can be found at http:// dx.doi.org/10.1016/j.micromeso.2017.02.029.

\section{References}

[1] T. Vosch, Y. Antoku, J.C. Hsiang, C.I. Richards, J.I. Gonzalez, R.M. Dickson, Proc. Natl. Acad. Sci. U. S. A. 104 (2007) 12616-12621.

[2] C.I. Richards, S. Choi, J.C. Hsiang, Y. Antoku, T. Vosch, A. Bongiorno, Y.L. Tzeng, R.M. Dickson, J. Am. Chem. Soc. 130 (2008) 5038-5039.

[3] H.X. Xu, K.S. Suslick, Adv. Mater. 22 (2010) 1078-1082.

[4] J.P. Wilcoxon, B.L. Abrams, Chem. Soc. Rev. 35 (2006) 1162-1194.

[5] L.A. Peyser, A.E. Vinson, A.P. Bartko, R.M. Dickson, Science 291 (2001) 103-106.

[6] J. Zheng, R.M. Dickson, J. Am. Chem. Soc. 124 (2002) 13982-13983.

[7] M. Walter, J. Akola, O. Lopez-Acevedo, P.D. Jadzinsky, G. Calero, C.J. Ackerson, R.L. Whetten, H. Gronbeck, H. Hakkinen, Proc. Natl. Acad. Sci. U. S. A. 105 (2008) 9157-9162.

[8] J.T. Petty, J. Zheng, N.V. Hud, R.M. Dickson, J. Am. Chem. Soc. 126 (2004) 5207-5212.

[9] A. Henglein, Chem. Rev. 89 (1989) 1861-1873.

[10] J. Yu, S.A. Patel, R.M. Dickson, Angew. Chem.-Int. Ed. 46 (2007) 2028-2030.

[11] M. Mostafavi, N. Keghouche, M.O. Delcourt, J. Belloni, Chem. Phys. Lett. 167 (1990) 193-197.

[12] M.D. Baker, J. Godber, G.A. Ozin, J. Phys. Chem. 89 (1985) 2299-2304.

[13] R. Seifert, R. Rytz, G. Calzaferri, J. Phys. Chem. A 104 (2000) 7473-7483.

[14] D.N. Theodorou, R.Q. Snurr, A.T. Bell, Comprehensive Supramolecular Chemistry, 1996.

[15] J.S. Woertink, P.J. Smeets, M.H. Groothaert, M.A. Vance, B.F. Sels, R.A. Schoonheydt, E.I. Solomon, Proc. Natl. Acad. Sci. U. S. A. 106 (2009) 18908-18913.

[16] V. De Waele, J. Kecht, Z. Tahri, M. Mostafavi, T. Bein, S. Mintova, Sensors Actuators B-Chem. 126 (2007) 338-343.

[17] A. Souici, K.L. Wong, V. De Waele, J.L. Marignier, T.H. Metzger, N. Keghouche, S. Mintova, M. Mostafavi, J. Phys. Chem. C 118 (2014) 6324-6334.

[18] G. De Cremer, E. Coutino-Gonzalez, M.B.J. Roeffaers, B. Moens, J. Ollevier, M. Van der Auweraer, R. Schoonheydt, P.A. Jacobs, F.C. De Schryver, J. Hofkens, D.E. De Vos, B.F. Sels, T. Vosch, J. Am. Chem. Soc. 131 (2009) 3049-3056.
[19] F. Luchez, Z. Tahri, V. De Waele, I. Yordanov, S. Mintova, A. Moissette M. Mostafavi, O. Poizat, Microporous Mesoporous Mater. 194 (2014) $183-189$.

[20] O. Fenwick, E. Coutino-Gonzalez, D. Grandjean, W. Baekelant, F. Richard, S. Bonacchi, D. De Vos, P. Lievens, M. Roeffaers, J. Hofkens, P. Samori, Nat Mater. 15 (2016) 1017-1022.

[21] F. Delprato, L. Delmotte, J.L. Guth, L. Huve, Zeolites 10 (1990) 546-552.

[22] A. Pal, S. Shah, S. Devi, Mater. Chem. Phys. 114 (2009) 530-532.

[23] G. Geudtner, F. Janetzko, A.M. Koster, A. Vela, P. Calaminici, J. Comput. Chem. 27 (2006) 483-490.

[24] G. Geudtner, P. Calaminici, J. Carmona-Espindola, J.M. del Campo V.D. Dominguez-Soria, R.F. Moreno, G.U. Gamboa, A. Goursot, A.M. Koster J.U. Reveles, T. Mineva, J.M. Vasquez-Perez, A. Vela, B. Zuninga-Gutierrez, D.R. Salahub, Wiley Interdiscip. Rev.-Comput. Mol. Sci. 2 (2012) 548-555.

[25] J.P. Perdew, K. Burke, M. Ernzerhof, Phys. Rev. Lett. 77 (1996) 3865-3868.

[26] P. Calaminici, F. Janetzko, A.M. Koster, R. Mejia-Olvera, B. Zuniga-Gutierrez, J. Chem. Phys. 126 (2007) 044108.

[27] N. Godbout, D.R. Salahub, J. Andzelm, C.E. Wimmer, J. Chem. 70 (1992) $560-571$.

[28] J.U. Reveles, A.M. Koster, J. Comput. Chem. 25 (2004) 1109-1116.

[29] J.L. Lievens, J.P. Verduijn, W.J. Mortier, Zeolites 12 (1992) 690-697.

[30] E.P. Ng, D. Chateigner, T. Bein, V. Valtchev, S. Mintova, Science 335 (2012) $70-73$.

[31] J. Texter, T. Gonsiorowski, R. Kellerman, Phys. Rev. B Condens. Matter 23 (1981) 4407-4418.

[32] W. Zheng, T. Kurobori, J. Lumin. 131 (2011) 36-40.

[33] B.G. Ershov, A. Henglein, J. Phys. Chem. B 102 (1998) 10667-10671.

[34] C. Hu, T.W. Peng, X.X. Hu, Y.L. Nie, X.F. Zhou, J.H. Qu, H. He, J. Am. Chem. Soc 132 (2010) 857-862.

[35] Z.J. Li, M. Flytzani-Stephanopoulos, Appl. Catal. B-Environ. 22 (1999) 35-47.

[36] S.G. Chiodo, T. Mineva, J. Phys. Chem. C 120 (2016) 4471-4480.

[37] I. Belharouak, F. Weill, C. Parent, G. Le Flem, B. Moine, J. Non-Cryst. Solids 293 (2001) 649-656.

[38] J.A. Jimenez, S. Lysenko, H. Liu, J. Appl. Phys. 104 (2008).

[39] T. Sun, K. Seff, Cheminform 25 (1994) 857-870.

[40] G.A. Ozin, F. Hugues, S.M. Mattar, D.F. Mcintosh, J. Phys. Chem. 87 (1983) 3445-3450.

[41] E. Coutino-Gonzalez, D. Grandjean, M. Roeffaers, K. Kvashnina, E. Fron, B. Dieu, G. De Cremer, P. Lievens, B. Sels, J. Hofkens, Chem. Commun. 50 (2014) 1350-1352. 